\title{
Gendered livelihoods and the politics of socio-environmental identity: women's participation in conservation projects in Calakmul, Mexico
}

\author{
Claudia Radel \\ claudia.radel@usu.edu \\ Department of Environment \& Society, Utah State University, Logan, UT 84322, United States
}

\begin{abstract}
Author Version
Citation for final published article:

Radel, C. 2012. Gendered livelihoods and the politics of socio-environmental identity: Women's participation in conservation projects in Calakmul, Mexico. Gender, Place, and Culture 19(1): 61-82. DOI:10.1080/0966369X.2011.617905.
\end{abstract}

\begin{abstract}
A livelihoods approach positions individuals, situated within households, as active agents within processes occurring at various scales. Environmental conservation efforts represent one such process with direct implications for local sustainable livelihoods and the gendered nature of livelihood strategies. In this article, I examine collective processes of socio-environmental identity construction as gendered sustainable livelihood strategies, articulated in and through the activities of women's agricultural organizations in communities bordering the Calakmul Biosphere Reserve in rural southern Mexico. I present group histories and visual evidence from group activities - adapted from participatory rural appraisal methodology - to highlight two important concepts. These are: (1) that gendered livelihood strategies are outcomes of negotiations within households and communities, in response to specific gendered opportunities and constraints; and (2) that gendered livelihood strategies consist of linked material and ideological aspects.
\end{abstract}

Key words: livelihood strategies; conservation; identity politics; women's CBOs; Mexico

Women and men adopt strategies in the pursuit of viable livelihoods in response to changing opportunities and constraints in specific places. These opportunities and constraints reflect processes occurring at various scales - from the household to the community, the state, and well beyond. I present a case study of one livelihood strategy of a number of women, to redefine (or reposition) themselves collectively as farmers as a means to legitimize participation in conservation projects. These women's farmer identities stand in contrast to a locally-dominant household position as housewife and/or agricultural helper to a male farmer. The collective repositioning as farmers on the part of these women occurred in the context of biodiversity conservation efforts in southern Mexico in the late 1990s to early 2000s, with an impact on the women's access to and control over land and conservation project resources. By considering the social constructions of people's relations to their environments (in this case through agriculturally-based labor and livelihoods) as the socio-environmental identities of farming, and linking these identities to resource outcomes, it becomes clear that the disruption of dominant identities can be an important gendered livelihood strategy.

In rural farming villages surrounding the Calakmul Biosphere Reserve, many women participated in community-based organizations (CBOs) of various kinds during this time period. 
These women collectively sought out access to resources through participation in projects funded by both governmental and non-governmental organizations. Many CBOs functioned primarily to funnel additional resources (such as project funds and materials) into households, and many were less than successful in the minds of women participants and their husbands. Occasionally, these CBOs have been more than vehicles to access material resources for households - they also have embodied strategies to locally reposition women as farmers. For women members of these particular CBOs, gendered socio-environmental identities of farming were remade dialectically within the projects: Success in acquiring project resources led to reconfigurations of identities and even greater success.

Since 2002, I have been working in the ejidos of a semi-subsistence agricultural zone surrounding Mexico’s Calakmul Biosphere Reserve. Ejidos are collective land units and associated villages, established under twentieth-century Mexican agricultural reform law. The Calakmul Biosphere Reserve was established in 1989 to protect 723,185 hectares of semideciduous (wet/dry) tropical forest. The park's establishment initiated a period of considerable project-based outreach, on the part of national and international conservationist interests, to the rural communities located next to and within park borders. Conservationists identified existing peasant farming practices and growing human populations as threats to park sustainability. Funds flowing from outside the region, constituting new material resources and configuring new social networks, were funneled to farmers in an effort to alter farming practices and to manage or reconfigure the human-environment relationship.

Non-governmental organizations, such as Pronatura Peninsula Yucatán and Bosque Modelo, and governmental bodies such as the Secretariat of the Environment and the Calakmul Biosphere Reserve office, worked to diversify households' production strategies under strict terms of environmentally acceptable outcomes. Certain livelihood-oriented land-use activities were seen as unacceptable (e.g. cattle ranching); while others were defined as desirable (e.g. diversified agroforestry). In addition, in response to national and international gender equity goals, the conservation organizations attempted to incorporate women, either within a focus on handicrafts production as a means to diversify household livelihoods away from agriculture and other land-based activities threatening forests, or within existing farmer-oriented projects encouraging alternative farming practices and land uses.

For certain women and their families, participation through a women's CBO in farmeroriented conservation projects became one component of a larger bundle of livelihood activities around farming. The need to supplement agricultural production for household consumption and market sale with other forms of cash income, or to subsidize that production with inputs provided by NGO- or government-sponsored projects, increased throughout rural Mexico beginning in the 1980s when state agrarian policy experienced neoliberal reform. By the latter 1990s (following the 1994 North American Free Trade Agreement), neoliberal policies permeated the countryside. Price supports for basic crops were eliminated, and inputs were no longer subsidized in the marketplace. Rural smallholders in Calakmul found themselves increasingly dependent on both conservation and development project funds (Klepeis and Roy Chowdhury 2004), as well as on state cash transfer programs such as Procampo, which aimed to cushion the neoliberal blow (Schmook and Vance 2009), and Oportunidades, a conditional transfer program for poverty alleviation (Winters and Davis 2009). One outcome has been the diversification of smallholder livelihood strategies (de Janvry and Sadoulet 2001), often with an increased incorporation of labor out-migration (Gravel 2007; Radel and Schmook 2008). 
Although gender-related goals of international donors and of certain interests within the state provided pressure to include some women as direct beneficiaries of projects, most conservation and development projects targeted men as farmers. In Calakmul, women as a social category are positioned as housewives ("me dedico al hogar" - I dedicate myself to the home), and men as farmers, as has been documented in Mexico more widely (Zapata 1996). As farmers, men in Calakmul control land-use decision making and land (Radel 2005) and receive most of the conservation project resources directed at farmers. The women who have been most successful in accessing project resources are those claiming farmer identities. Employing the theoretical frameworks of gendered livelihoods and feminist political ecology and a qualitative research method adapted from participatory rural appraisal, I seek to understand this aspect of women's changing livelihood strategies in the region during the conservation project period of the late 1990s and early 2000s. Drawing on the literature, I highlight both the conceptual intersection of gender with livelihood production strategies and asset-based approaches to poverty reduction and the intersection of gendered environmental resource access and control with socio-environmental identity. I then present the comparative histories of four women's CBOs along with drawings by CBO members. Through these histories and drawings, I explore the relationship between women's collective livelihood strategies and a politics of gendered socio-environmental identities. In concert, I discuss these women's access to land and conservation project resources.

\section{Livelihoods as gendered}

Our livelihoods, or how we make a living, are central to who we are, where we fit into our society and into increasingly-global economic systems, and our material wellbeing. Through our livelihoods we engage and interact both with other people and with our environments. Chambers and Conway (1991) laid out a conceptual framework for sustainable livelihoods as a combination of (1) people, including their abilities; (2) people's activities, or what they do (and we might also say their practices); and (3) people's assets, or what they have (both tangible stores and resources and intangible claims and access). People, their activities, and their assets combine to form a living, which we tend to think of in material terms, producing food, shelter, and other consumption goods. The sustainability of the produced livelihood has both environmental and social aspects, and depends on an ability to “...cope with and recover from stress and shocks, maintain or enhance its capabilities and assets, and provide sustainable livelihood opportunities for the next generation” (Chambers and Conway 1991, 6). More importantly in the context of this case study, sustainability is increasingly constructed in terms of social justice as well as environmental resilience (Fleming 2009), which necessitates an examination of gender-based inequalities. However, recent application to poverty alleviation and community development has largely adopted a capital assets approach to livelihoods. Although different configurations and categories of capital have been posited as important to livelihoods, a list might include human, natural, produced/physical, social, political and financial (Rakodi 1999). The result has been an increasing focus on people's assets and a decreasing focus on people's practices. The benefit of an assets-based approach for questions of poverty alleviation is that it starts from what the poor have instead of what they lack. However, as a consequence, gender as a practice within the context of livelihood production has been relatively obscured. 
As a basic category of social differentiation, where does gender fit into these asset-based frameworks? Clearly, gender conditions differences in stores of and access to different types of capital (Flora 2001). For example, if we examine an individual's human capital, we might see significant differences in achieved formal education and in access to health care based upon gender status. Adapting a diagram of the components and flows in a livelihood (Chambers and Conway 1991), it is useful to conceive of these elements as being embedded within a larger social structure. In conceptualizing the gendered nature of livelihoods, this larger social structure specifically includes a dominant gender ideology ${ }^{1}$ (Figure 1). We can then conceptualize the dominant gender ideology as impacting the size and/or quality of the component circles, aspects of which are well studied. For example, considerable research exists on women's differential access to and control over natural capital such as land (Razavi 2003), including in Latin America (Deere and Leon 2003). Numerous other scholars have looked at how women's stores of and access to social capital might be different from men’s, in degree or type (Godquin and Quisumbing 2008; Molyneux 2002; Silvey and Elmhirst 2003).

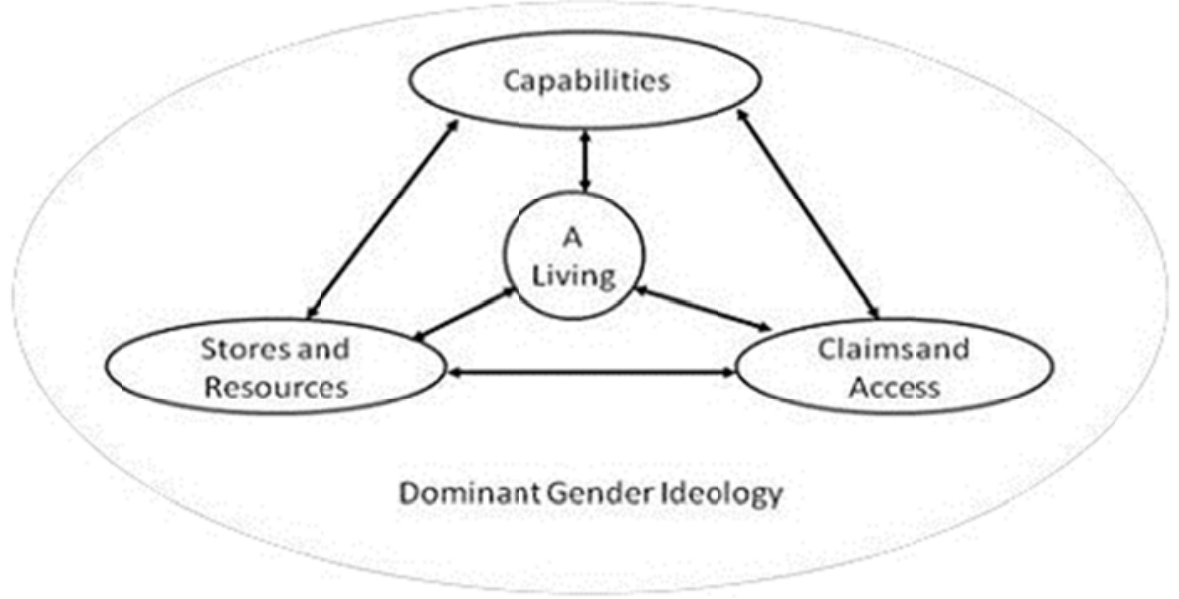

Figure 1. One conceptual approach to gendered livelihoods, as adapted from Chambers and Conway (1991).

Although very important, a focus on assets tends to overshadow and obscure the activities or practices that people, including women in collectives, carry out. Many of these activities have a significant ideological component, and this is a very important part of understanding livelihoods as gendered. Oberhauser, Mandel and Hapke (2004: 206) state: “...livelihood strategies involve transformative struggles through which women work to empower themselves by reshaping their identities, lives, and relationships within households and communities," and call for more empirical work on these practices. Others also have identified the need for a livelihoods perspective to include people's struggles over identity (Jackson and Chattopadhyay 2000). In the case study I present here, I particularly highlight how daily practices of the women in question, through their collective activities, constitute a critical component of livelihood production. Although I do not detail daily activities per se, the histories of the CBOs are constituted by the members' daily and ordinary activities in the context of the group. We can see these practices, although linked to asset-building goals, as essentially ideological in nature. 


\section{Feminist political ecology, gendered resource access and control, and the politics of socio- environmental identity}

I use the idea of socio-environmental identities to refer to the social constructions of people's relations to their environments through their labor, their livelihoods, and/or their environmental ethics, in a specific socio-political context of environmental resource rights. ${ }^{2}$ By characterizing, socio-environmental identities as gendered, I am stressing the interaction between the social construction of people's relations to their environments and the social construction of gender. Likewise, socio-environmental identities are sexualized (Sandilands 2005) and racialized (Sundberg 2004).

Feminist political ecology (FPE) (Rocheleau, Thomas-Slayter, and Wangari 1996) developed in the 1990s as one of several alternative theoretical approaches to understanding human-environment relations as gendered. As a response to certain strands of eco-feminism, FPE filled a need to theorize the role of gender without essentializing the relation between women and environments (Leach 2007). FPE approaches human-environment relations as encompassing a myriad of material and ideological relationships, including socio-environmental identity as defined above. From its inception, FPE has drawn upon empirical field research in gender and the environment and a constructivist feminist theory of gender identity and science. As an approach, it grounds an understanding of women's relation to the environment in the material, historical, socio-cultural and political realities of specific places. Rocheleau, Thomas-Slayter, and Wangari (1996), in the first and only comprehensive articulation of the FPE framework, outlined three analytical themes: (1) gendered knowledge, (2) gendered environmental rights and responsibilities, and (3) gendered environmental politics and grassroots activism. Since then, FPE has continued within geography as a relatively open theoretical framework (much as political ecology has) embracing most human-environment scholarship which treats gender as an important variable of analysis. As a body of theory, FPE to date remains under-specified, perhaps purposely so.

The strategic deployment of identity in relation to asset access and control has been examined by a number of political ecologists, including but not confined to those employing an FPE framework. These scholars have examined how identity is mobilized to assert resource claims, including land claims (Mollet 2006; Perreault 2001; Pulido 1996) and claims to development or conservation project resources (Sundberg 2004). Much of the research has centered around indigenous environmental identities. Sundberg developed the concept of identities-in-the-making and examined how simultaneously gendered and racialized environmental identities are both produced and enacted through conservation projects in Guatemala (2004). Actor agency has been central in this scholarship. Women's agency in redefining gendered identities in relation to environments was recognized as important within Rocheleau and colleagues' FPE framework (1996, 15), and a conceptual understanding of strategic identity deployment as variously principled, contingent, and/or instrumental rejects a dichotomy of socio-environmental identity as either authentically essential or deceitfully strategic (Rocheleau and Radel 1999).

Another important analytical thread within FPE and political ecology more broadly has been the examination of how resource rights are negotiated between men and women both within households and villages. Much of this research has focused on resources key to livelihoods 
production such as land and trees (Carney 1993; Rocheleau and Edmunds 1997; Schroeder 1999). Bassett (2002), in his work on cash cropping in the Ivory Coast, for example, points to how women not only negotiate within the household in order to farm their own cotton, but need to negotiate access to productive inputs at the village scale as well. Through this empirical research, these researchers have documented the ways that conservation and agricultural development policies and projects can play a role in these negotiations. This article's case study adds to the evidence of the role that conservation and conservation actors play in both community and intra-household gender relations. Although in this article I do not emphasize the relations within households, focusing instead primarily at the community level, a diversity of household relations position the CBO member women differentially within CBOs (and also position some women completely outside of the CBOs, as some husbands forbid wives' participation).

In examining the connection between gender relations and environmental relations, there has been growing emphasis in FPE on mutual construction, with a particular stress on the importance of the ideological, including identity, in concert with the material, in the creation of gendered environmental relations (Gururani 2002; Nightingale 2006; Rocheleau et al. 2001). Attention to the ideological in concert with the material has emphasized men's and women's agency in identity construction and its material consequences. Clear parallels on the intersection of gender identity and material resources for farming can be found in the Global North. For example, research has exposed the highly gendered nature of farming in countries such as Australia (Liepins 2000) and the United States (Sachs 1983; Trauger 2004). My analysis of the case study described here has been informed by this research and aims to specifically explore the role of collective agency (in this case, on the part of certain women's groups) to challenge a dominant ideology of gendered environmental relations (“only men are farmers”). I explore the activities of women's CBOs as livelihood strategies, with material goals, and - in some cases - a dialectical relation to member women's socio-environmental identities in the context of the group.

\section{The Calakmul case study}

In 2002, I visited 41 rural communities surrounding the Calakmul Biosphere Reserve, meeting with residents and community leaders. These communities (all but three of which are ejidos) flank the park's eastern border and the main highway that bisects the reserve east to west through the center of the Reserve (Figure 2). I selected three of the ejidos - La Verdad, Nueva Esperanza, and El Futuro ${ }^{3}$ - as case study communities in which to spend extensive time carrying out research. These villages represented a range of women's collective action, from fairly minimal to unusually extensive, and are best characterized as mestizo, the dominant ethnic identity in this region. ${ }^{4}$ The research, framed by FPE, covered broad issues on gendered access to and control over resources, particularly land, the gendered division of agricultural labor and decision making, and community and household gender relations. During a 12-month period of time, I lived with my husband and two-year-old son in one of the non-case-study communities, interacting with NGO and state agency personnel. 


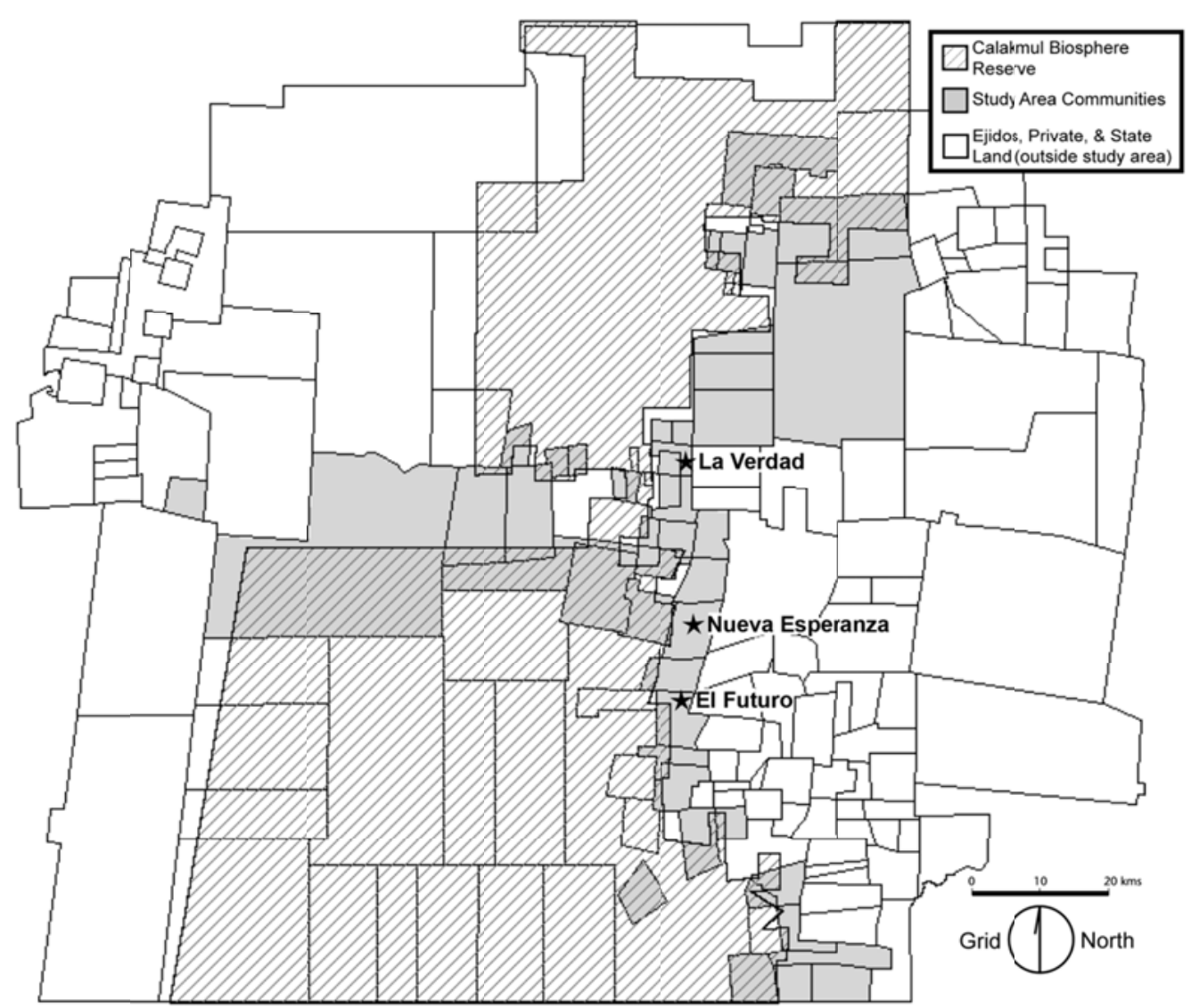

Figure 2. The larger study area and the Calakmul Biosphere Reserve.

In the three case study ejidos, I carried out semi-structured interviews with women from 100 randomly selected households, stratified by community and by participation in a women's CBO. These interviews lasted from one to three hours, depending on both the woman's interest and the topics I wished to pursue with her. These interviews provided me with an underlying insight into gendered farming and gender relations in these particular villages, from the perspectives of the women themselves, and I report on these interviews elsewhere (e.g. Radel 2005, 2011, 2012). More specifically germane to my purposes here, I carried out various activities with the five women's agricultural CBOs active in the three villages and present results from four of these CBOs in this article. ${ }^{5}$ These four CBOs were organized under different legal frameworks for collective action in Mexico's rural communities: Three were unidades agroindustriales de la mujer (women's agro-industrial units, or UAIMs) and one was a sociedad productiva rural (productive rural society). I regularly attended the meetings of these CBOs over the course of a year, participated in group activities, and accompanied the women to group fields. I also engaged in informal conversations, interviewed the leaders extensively, ${ }^{6}$ and organized activities based on my own training and experience in participatory rural appraisal (PRA). ${ }^{7}$ The results of two PRA-like activities (described in more detail below) form the primary basis of this article.

PRA evolved in part out of the 1970s and 80s practice of rapid rural appraisal, an approach designed to enable development field practitioners to quickly elicit information and 
knowledge from rural inhabitants (Chambers 1994b). The shift to participatory, as opposed to rapid, rural appraisal had as its emphasis the active agency of rural inhabitants as co-creators of knowledge, through activities that also served to inform and empower participants. This empowerment has been contrasted with other research methods whose primary aim is to extract information from participants. According to Chambers, PRA as a method of development practitioner interaction with community residents results in significant reversals: "Modes of interaction and analysis are reversed from their normal directions in three ways: from individual to group; from verbal to visual; and from measuring to comparing” (Chambers 1994a, 1263). These reversals can contribute new and important insights for research. Unfortunately, the use of PRA in academic research, such as presented in this article, does not hold true to the primary intentions of PRA - catalyzing action for change. For this reason, I refer here to my methods as PRA-like activities. Nonetheless, translating the results of the activities in which I and the women engaged into scholarly insight does not preclude the facilitation of critical learning for action in the sense put forth by Freire (1986).

I engaged the women in PRA-like activities on various separate occasions. ${ }^{8}$ For one activity, we reconstructed the history of the group and its activities over the years since formation, creating and ordering colored cards and drawings. Input from numerous different members led to a more complete and accurate collective memory of each group's history. These detailed group-created histories are the basis of comparative summary histories I recount below for each CBO, supplemented with additional information from various interviews, including with present and former CBO leaders.

In another PRA-like activity, I asked each woman to individually draw a self-portrait, depicting herself engaged in an activity that she saw as important to who she was as a woman. To assist the women in understanding what exactly I might mean by this, I drew a picture of myself holding a clipboard in one hand and toy truck in the other hand. By my side, I drew my two-year-old son, who was living with me in the field but who did not accompany me to these meetings or to interviews. ${ }^{9}$ I then briefly and orally annotated the drawing, explaining how my dual roles as a researcher and a mother were important in defining who I felt I was as a woman. My goal in this activity was to gain insight into how the women viewed themselves as women, or more accurately, to learn how the women would choose to represent themselves to me within the context of the group. It is important to note that the drawing of the self-portraits was accompanied by light conversation, frequent sharing among the women of drawings in process, and considerable laughter. As a result, the drawings are perhaps best viewed as the result of both an individual and a collective process and the very nature of the drawings reflects some groups' roles in the women's re-imagination of individual identities as farmers, within the context of the $\mathrm{CBO}$ and its project activities. The portraits also inevitably include an aspect of responding to my own sample portrait and of reflecting back the women's own perceptions of what I wanted and their desire to provide it to me (both as a friend and potentially influential outsider). This is a natural outcome of research, whether we ask our "subjects" to draw for us, to speak with us, or to perform for us. The exchange itself shapes the understanding of both the researcher and the researched. Keeping these points in mind, we should interpret the women's self-portraits as dynamic portrayals, fixing in space and time an identity which is relational and non-fixed. Remembering theoretical understandings of identities, including socio-environmental identities, as context-specific and as outcomes of social exchanges and relations leads me to readily embrace these portraits for both what they are and are not. 
I found it informative to divide the self-portraits drawn by each woman member of the four CBOs (depicting herself engaged in an activity that she saw as important to who she was as a woman) into two categories: those that conformed to dominant gender role ideology and those that transgressed it. In many of the CBOs, a majority of women drew themselves carrying out "female" labor tasks, such as feeding fowl just outside the home, fetching water for cooking and cleaning, and caring for children. These drawings represent a depiction of women's identity in line with and reinforcing the dominant gender ideology. There is a clear emphasis on reproductive labor, and any depiction of productive labor ${ }^{10}$ is restricted to specific spaces: the house and the home garden that surrounds it. In the second category of drawings, the women explicitly drew themselves as farmers. One woman depicted herself operating a roto-tiller; ${ }^{11}$ while other women drew themselves using a machete out in the fields, harvesting Canavalia (a nitrogen-fixing legume promoted by some of the conservation projects), or engaged in other field-based labor. The women that completed these drawings did not depict themselves helping men. They drew themselves as farmers in their own right. These drawings transgress local gender ideology in which men are defined as farmers and women are defined as housewives and agricultural helpmates.

\section{The women's community-based organizations: group histories and self-portraits}

\section{The UAIM in La Verdad}

The UAIM is an institutional framework for women's collective organization, labor, and land access created under Mexico’s agricultural reform laws and the ejidal structure (Arizpe and Botey 1987, Zapata 1996). Beginning in 1971, every ejido was required to set aside a parcel of ejidal land for use by women organized into a UAIM (although some ejidos in the study region did not comply until over a decade later). The UAIM in La Verdad in 2002 was a second iteration of the group. In the mid-1980s, women in the ejido formed a UAIM and received financial support to cultivate maize and beans on the almost 20-hectare UAIM parcel that lies at the edge of town. Interviewed residents report that this first attempt at women's collective organization and cultivation failed after the first year, primarily due to a lack of support within households and within the village.

In 1992, the UAIM re-formed and re-cleared the parcel. The second formation of the UAIM came about as the result of encouragement by the male ejidal leadership, particularly encouragement from one wealthy farmer well connected to local government and to local representation of the state. He called a community meeting and informed the wives of ejidatarios $^{12}$ of an opportunity to receive fruit (citrus and non-citrus) and hardwood (cedar and mahogany) tree seedlings for planting on the abandoned UAIM parcel. The La Verdad UAIM thus re-formed, with the approval and support of men, to take advantage of a specific opportunity to gain access to resources, the seedlings, and improve the productive value of the UAIM parcel. Families interested in participating contributed labor, primarily male, to re-clear the parcel of secondary growth. Then the ejidal assembly ${ }^{13}$ divided the parcel into 19 one-hectare plots and allocated these to 19 women. The initial tree-planting project was followed throughout the 1990s with additional projects, resulting in significant inflow of both materials and cash. In addition to receiving many more tree seedlings, the group received a roto-tiller, built a house for meetings and workshops, received a project to make and apply organic fertilizer, and received various payments for labor on their plots (for tree maintenance, for example). By 2002, more than 14 
organizations had worked with and supported the UAIM since its formation. From the beginning, La Verdad residents and leaders constructed the UAIM as a medium for external-benefit flows to individual households, leading to conflicts over the distribution of these benefits and a politicization of participation.

Critical in achieving these project benefit flows was the role of a woman agronomist, who initiated activities with the UAIM in 1994. The agronomist's participation with the UAIM, first as a environmental educator with Pronatura Peninsula Yucatán (a regional environmental NGO) and then as a MacArthur Fellow, lasted roughly six years and focused on two areas: soil improvement of the UAIM parcel and the "personal development" of the UAIM women. This personal development took the form of numerous meetings and workshops on what is locally referred to as autoestima (self-esteem), in which the agronomist attempted to address perceptions of gendered self-worth and abilities, as well as intra-household gender relations, including domestic abuse. The agronomist shared with me that men within the ejido initially resisted her work with the women, but that this resistance dissipated as direct household benefit in the form of project cash and goods became more apparent.

During my field work period, rumors floated that the men had taken over control of the UAIM parcel in La Verdad. Some agricultural activities had been transferred from the parcels of the male ejidatarios to the one-hectare UAIM plots, and knowledge of these labor transfers fed the rumors. My interviews uncovered that some men had transferred the majority of their labor to the UAIM plots because the plots were much closer and easier to reach than their 20-hectare ejidal parcels, and others had done so because of perceived greater returns to labor on the UAIM plots. In addition, some UAIM plots had always been under the control of men, with the husband or father controlling both land-use decisions for and benefits from the land (Radel 2005). It is telling that these male-controlled UAIM plots are referenced within the village by the man's name as opposed to by the woman's name. This naming reflects the range of intra-household gender relations around the UAIM parcel and project benefits within La Verdad.

For their self-portraits, the women were fairly evenly divided between those who drew themselves engaged in household tasks commonly carried out by women (five cases) (e.g. Figure 3 ), and those who drew themselves engaged in farming tasks on their UAIM parcels (six cases) (e.g. Figure 4). This diversity appears to represent well the diversity among women within the village, their relative positions within their households, and the contradictory history of the UAIM itself encompassing both a prolonged effort by the outside agronomist to transform women's positions within households and the village and the role of particular men in the history of the group and in the control of a number of individual UAIM plots.

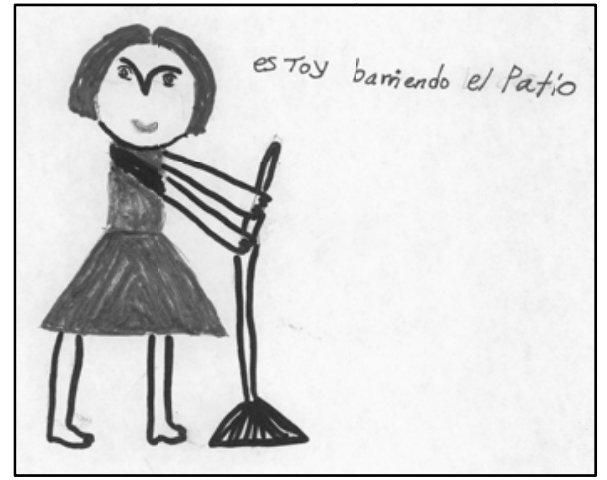

Figure 3. Self-portrait of a member the La Verdad UAIM: Sweeping the yard. 


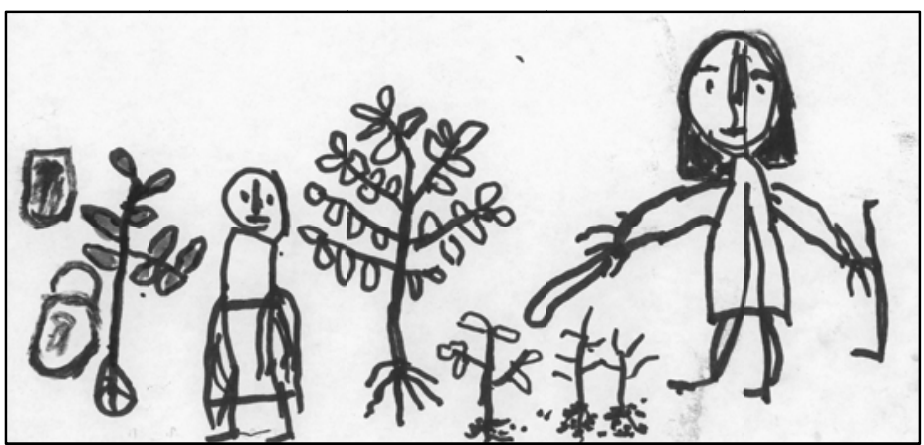

Figure 4. Self-portrait of a member the La Verdad UAIM: Working on the UAIM plot, accompanied by daughter. Note the machete and tree trimming tools, the growing tree and annual crops, and the unplanted tree seedling.

\section{The UAIM in El Futuro}

The UAIM in El Futuro has a quite different history from the UAIM in La Verdad. This UAIM was formed around 1983, after a woman came across information about UAIMs in a book her husband had borrowed from friends at the Secretariat of Agricultural Reform. This woman organized a group of 32 other women, petitioned the ejidal assembly for land, and received 20 hectares. From the start, the women lacked widespread male support within the village. The women cleared all 20 hectares on their own and began cultivating chili and maize on around five of these. They intended to plant the remaining parcel in pasture and had arranged to receive credit for fencing and 100 ewes. They also organized village dances and parties to raise money for their group. In reflecting on this early period of the UAIM's history, the founder and first president related to me that many people in town did not support them in their activities, saying that they were acting like they wanted to be men. By 1986, serious conflict within the ejido forced the resignation of the CBO leaders, including the president. The bank deal for the fencing and sheep fell through, and women dropped out of the group.

Following the conflict, the UAIM divided up the parcel and continued to operate only nominally for many years. When the UAIM began receiving direct state cash transfers in 1993, through Procampo, ${ }^{14}$ a new group of women argued that they should be allowed to join the UAIM in order to gain access to these payments. UAIM membership fluctuated, but by 2002 the UAIM had 18 members, with each member allotted one hectare. Most women, or their husbands, were clearing their plots each year, as this was a stipulation for receiving Procampo payments, but many did not bother to cultivate their plots. In some households - mainly those with no other land or an ejidal parcel far from the village - the men regularly planted the hectare UAIM plot with chili. A few other men had planted papaya trees in some UAIM plots, and they actively maintained them.

The El Futuro UAIM began through strong local women's initiative and collective organization. Over a short period of time, however, the CBO suffered problems of internal and village conflict that the members were unable to surmount. Subsequently, UAIM members failed to secure any substantial flows of project resources. By 2002, the group resembled many other UAIMs throughout the Calakmul region: The parcel as a whole was ostensibly cleared annually to secure transfer payments, but cultivation of UAIM land was limited to a small subset of the members, and collective livelihood efforts were plagued by numerous group and village 
conflicts. In addition, a number of men actively and openly farmed the UAIM parcel. When the El Futuro UAIM women drew their self-portraits, all the women (eight were present for the activity) drew themselves engaged in traditionally female tasks (e.g. Figure 5), and not one woman drew a picture of herself as a farmer, working on "her" UAIM land.

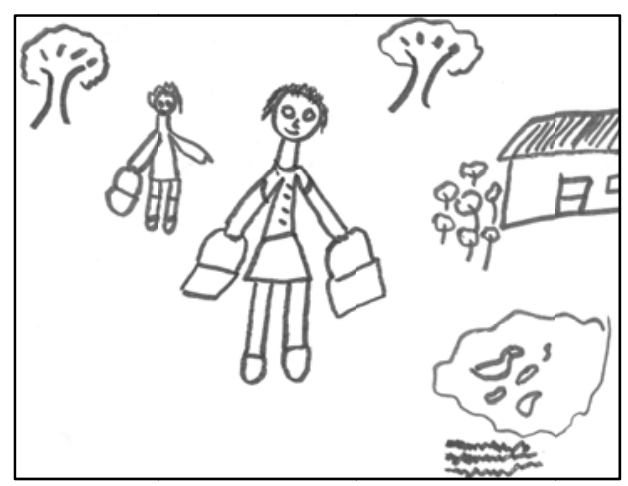

Figure 5. Self-portrait of a member the El Futuro UAIM: Fetching water for cooking and cleaning.

\section{The UAIM in Nueva Esperanza}

Nueva Esperanza also has a UAIM, along with two other women's CBOs. The UAIM was formed around 1980, when employees of the Secretariat of Agricultural Reform arrived with the specific goal of supporting the establishment of a UAIM. Prior to that point, few women realized that the ejidal assembly had already designated a 20-hectare parcel for that purpose, as required under agricultural reform law. Little group activity occurred through the 1980s, and in 1990 the women divided the UAIM parcel into half-hectare plots for individual cultivation. In 1995, UAIM leaders enrolled the UAIM parcel in the Procampo program. The receipt of Procampo payments increased interest in UAIM membership, leading the women to further divide the land. In 2002, around 60 members had access to 0.375 hectares each, and most members received approximately $\$ 250$ pesos each per year through Procampo. This payment appeared to be the primary motivation for the continued existence of the CBO, and interviewed UAIM members felt that they had achieved "nothing" as a group. Of the 15 women who participated in the selfportrait activity, 14 drew themselves engaged in traditionally female tasks (e.g. Figure 6).

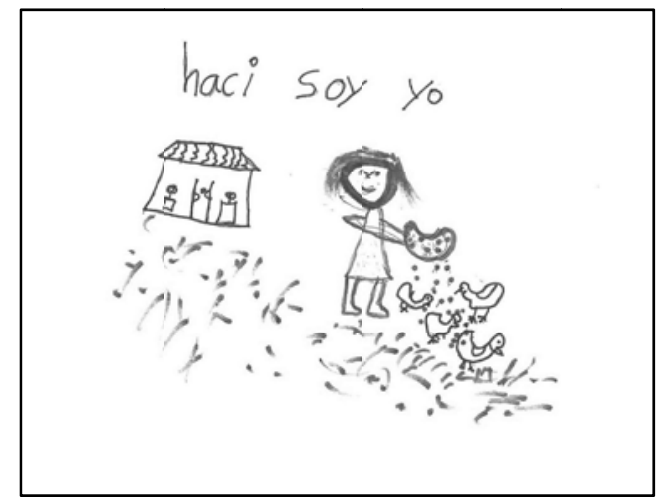

Figure 6. Self-portrait of a member the Nueva Esperanza UAIM: Feeding fowl outside the home. 


\section{The "Society of Farming Women for Sustainable Development" in Nueva Esperanza}

A member of the Nueva Esperanza UAIM was required to relinquish UAIM membership when her husband abandoned her and the ejidal assembly voted to transfer his ejidal land right to her (to be held by her for her eldest son). In 1997, she formed a new women's CBO. She began by inviting participation of all other ejidatarias (women holding ejidal land rights in their own names), as well as a number of friends and neighbors (many of who came from households without land rights). The group founder states that she started the group so that women, as well as men, could get access to project resources. She believed that the ejidatario men were leaving the ejidataria women out of various financial supports flowing into the ejido: “...the ejidatarios said no... the project supports coming into the community are for men...although we women need to work.” By 2002, this CBO had received a series of project supports from various organizations, including many conservation-oriented ones.

Initially, the women began collectively working land, planting trees, and raising sheep on land borrowed from one of the group's member ejidatarias, with cash and material support from the Secretariat of Rural Development's Women in Solidarity program. The borrowed land arrangement led to some internal conflicts and a sense of insecurity on the part of the members who did not own the land. So, in 1999, the women formalized their group as a rural society and a number contributed to the purchase of a 10-hectare parcel. The women named their group "Sociedad Mujeres Campesinas para el Desarrollo Sostenible" ("Society of Farming Women for Sustainable Development”). At this point, due to a lack of the financial means to participate in the land purchase, some women left the CBO and others remained in the group, but without participation in the subsequent land cultivation. The women mechanized five of the 10 hectares for the collective cultivation of chili. On the remaining five hectares they cultivated maize and beans. They recounted to me the difficult period of initial land clearing and recalled the derision they faced in the village when they first began doing this and other "male" farming tasks. By 2002, with the financial assistance of various entities including conservation NGOs, they had purchased a roto-tiller, which they used to prepare the soil on the mechanized portion of their parcel. A few of the women used this machine themselves, connecting to their sense of themselves as farmers (Figure 7), but often the women hired and supervise male relatives to operate it.

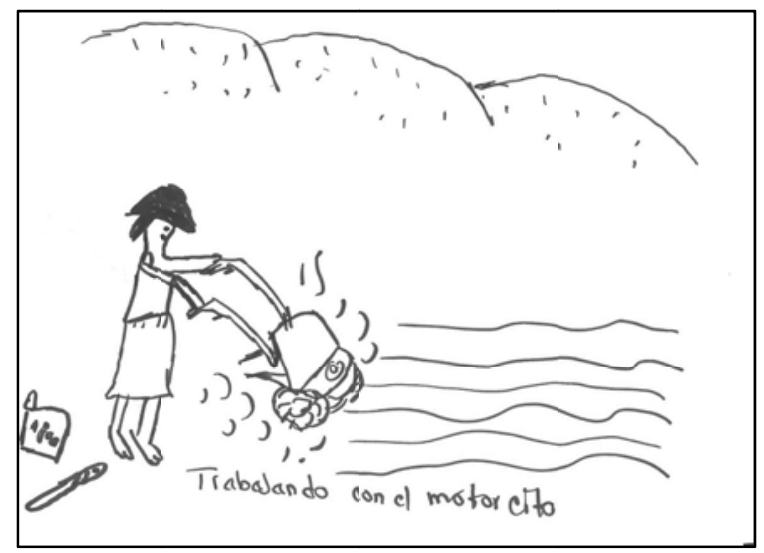

Figure 7. Self-portrait of a member of the Society of Farming Women for Sustainable Development in Nueva Esperanza: Operating the roto-tiller. 
The group actively sought opportunities to engage with conservation projects, for example, regularly planting the legumes "nescafé” (Mucuna pruriens) or Canavalia on their parcel and receiving labor payments and seeds from the Secretariat of the Environment. By 2002, the Society of Farming Women had accessed successfully an almost continuous flow of conservation-oriented project funds and was relatively well known throughout the region. They had just initiated a relationship with La Naturaleza Compartida (a small local environmental NGO), which facilitated their receipt of considerable project funds (approximately US\$25,000) from the United Nations Development Program and the Global Environment Facility. Unsurprisingly, this financial success and the inflow of project resources bred jealousy within the ejido and led to confrontations between the CBO president and the male ejidatarios over control of external funds received by the women. The group maintained its independence from the ejidal assembly, however, at least in part due to their connections to important outside organizational actors - connections established through their project participation.

The strong female leadership and goals behind the formation of the group, with an emphasis on accessing resources for women, and the division in the background of the members (women already with land in their own name and women from primarily landless households) are reflected in the results of the drawing activity: 11 women drew themselves as farmers (e.g. Figures 7 and 8), while eight did not. Group efforts to foster collective identities as farmers are reflected in the group's name and in their regular trips together to carry out collective farm labor on their land. Cultivation decisions are made together as women, during group meetings, with few to no men present.

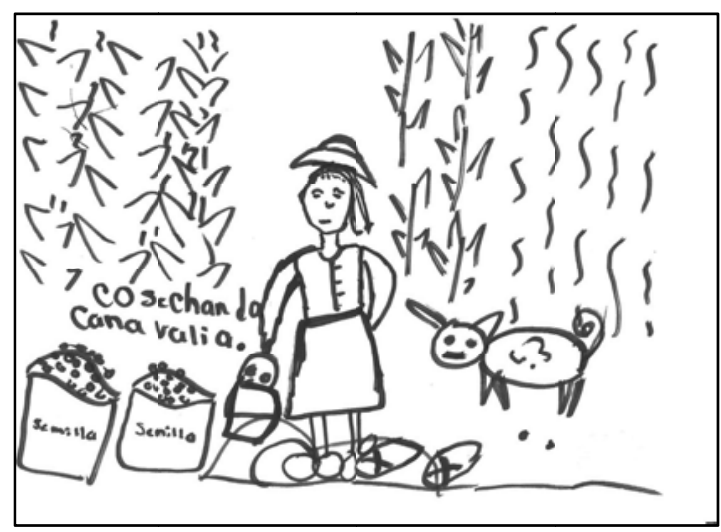

Figure 8. Self-portrait of a member of the Society of Farming Women for Sustainable Development in Nueva Esperanza: Harvesting Canavalia.

\section{Becoming farmers}

Who qualifies as a farmer is important, because in Calakmul to be a farmer is to have a right to land and a right to government assistance for farmers. Forests are viewed as places of work (Murphy 1998) - men's work - and working land is the ultimate socio-cultural claim to rights over that land (Haenn 1999). In Mexico, to farm is to have a right to land. More recently, as discussed earlier, being a farmer in Calakmul also carried a "right" to conservation project resources. Women's CBOs asserted claims to both land and project benefits by transgressing 
local gender norms, and gendered expectations of who is a farmer and who is not. The selfportraits of women as farmers in their own right depict an aspect of group socio-environmental identity which was configured in terms of productive labor and which had clear livelihood implications.

Two of the four women's CBOs discussed here - the "Society of Farming Women for Sustainable Development” in Nueva Esperanza and the UAIM in La Verdad - participated in many different conservation projects over the last decade, while the other two did not. These two CBOs also had an element in their histories as groups which emphasized a transformation of village gender relations. Perhaps not surprisingly then, these two CBOs had a relatively high proportion of the transformative drawings of women as farmers; while the other two groups had a much higher proportion of drawings conforming to dominant gender ideology. Some degree of reinforcing dynamic likely developed for the two CBOs, as group members were increasingly likely to see themselves as farmers as a result of project activities, and in turn increasingly laid claim to projects and land successfully under these terms. Yet even in these two CBOs, numerous women drew themselves engaged in more traditionally female tasks, pointing to the lack of homogeneity within the CBOs due to differences among the women members and their respective positions within their own households and within the village.

Nonetheless, as collectives these two CBOs differ in a meaningful way from the other two case-study CBOs. The "Society of Farming Women for Sustainable Development" in Nueva Esperanza and the UAIM in La Verdad provide illuminating cases for an exploration of how women might strategically construct and represent their socio-environmental identities, or their relationships to natural resources (land) through social roles (farmers). Via the mechanism of collective action, this construction and representation occurred as an integral part of accessing conservation project resources available to farmers in the region. Women's participation in farmer-oriented conservation projects facilitated access to and the mobilization of different types of capital, by providing project money and materials (such as trees and seeds), legitimizing access as women and families to land, and tapping into a growing local conservation network. However, as the group histories illustrate, the participation of the women's CBOs in the projects and the right of women to the associated livelihood benefits remained highly contested within the villages.

This right also remained highly contested within households, or contingent to the outcomes of intra-household negotiations. As a generalization, women's groups across Calakmul accessed project capital during this time period on behalf of households - households which in turn embodied a range of intra-household gender and age relations. Women's participation in the projects, and what then happened to the capital accessed, was subject to negotiations between men and women ${ }^{15}$ within households. I report elsewhere on the intra-household divisions of decision-making control over these resources (Radel 2005, 2012).

At both the village and household levels, women's CBO participation reflected the realities of gendered constraints and opportunities for both women and men. In Calakmul, one of the highly gendered constraints was the distribution of land and land-control. Land was largely controlled by men, with men holding $90 \%$ of the ejidal land rights and dominating household land-use decision making (Radel 2005); yet access to land was necessary for participation in the conservation projects. Although women's group land was ostensibly under the control of the member women, effective control - defined in terms of decision-making control and rights to crop and tree products - did not necessarily accompany the land's status as women's CBO land. The situation with the UAIM land and its use in El Futuro exemplified this reality. The right of 
the group and of the individual women to that land needed to be legitimized within the eyes of the village and its male leaders. Conservation project participation could provide this legitimacy and could also provide the necessary inputs to cultivate that land. At the same time, a lack of effective control over the UAIM parcel may have hindered the women's ability to secure a conservation project for that land.

In the cases when women's CBOs did secure conservation projects, group members experienced an increase in livelihood assets in general. Project participation increased and legitimized women's access to and control over land ${ }^{16}$ in the ejidos, provided women with financial and material capital like roto-tillers and tree seedlings, and also resulted in payments for labor in the field (planting soil-improvement crops like Canavalia). Projects also expanded and qualitatively changed participating women's social networks, both through the women's CBO activities and through groups' growing linkages outside the communities to a wider conservation and government network.

Although it has been true overall that securing conservation projects led to material benefits for the women, a high amount of variation occurred among the different CBOs and among the members of any given CBO. Some CBOs were very successful in both getting and then leveraging projects; while others were much less successful. One explanation for success in securing multiple projects is that conservation staff like to bet on winners, so to speak: that is, established community groups, with established project track records, attract additional project support. Haenn (2005), with research in similar ejidos surrounding the Calakmul Biosphere Reserve, notes the contradiction that this created for groups approaching conservation projects as livelihood activities: Groups had to demonstrate success and simultaneously demonstrate ongoing need. However, "success bred success" in this case precisely because the women became farmers in the process, solidifying their right to project resources.

What does this tell us about livelihoods as gendered in Calakmul? It is particularly illuminating that group activities for two women's CBOs were always about more than asset improvements for households. Through key actions by either their leader (in the case of the "Society of Farming Women") or an outside facilitator (in the case of the La Verdad UAIM), the women members began developing a group identity which was explicitly both gendered and environmental. In the example of the "Society of Farming Women for Sustainable Development," the women even chose a name to reinforce this collective gendered, socioenvironmental identity of farmer. In both cases, the women engaged in activities that included the goal of transforming what it means to be a farmer in their village. Identities of women as farmers challenge and potentially transform broader patterns of access to resources for farming livelihoods. The connection of socio-environmental identities to land and project benefits links ideology with material outcomes in the rural Latin American landscape.

\section{Conclusions}

Linked ideological and material aspects of agency are particularly important to our understanding of the collective action of rural women in the research I present here. Active identity construction, or how the women represented themselves within the spaces of the CBOs and the conservation projects, is central to this agency. Geographers and others have advocated the analytical inclusion of identity in working to understand resource claims and struggles, including claims by women, partly as a means to balance agency and structure considerations. 
Jackson (1998, 317), for example, has argued that strictly materialist approaches can ignore the agency of people: "Understanding, and unsettling, processes of power and exclusion that disadvantage women require attention to struggles over meaning as much as struggles over resources.” Arguably, this theme linking the ideological and the material in livelihood strategies is still emerging within political ecology theory, and FPE has much to offer in this effort.

This study stands as one response to calls such as the one put forth by Oberhauser, Mandel and Hapke (2004) - as an effort to better empirically ground our understanding of transformative struggles as livelihood strategies reshaping identities, lives, and relationships in an interaction with dominant gender ideology. In this article I seek to contribute to our understanding of how livelihoods are gendered and the role gender plays in changing livelihood strategies in rural communities of the Global South. How can this case study of women's participation in conservation projects in Calakmul help us in thinking about livelihoods as gendered? Stepping out of the still-dominant household unit of analysis is necessary for achieving an understanding of livelihoods as gendered. One way to achieve this is to switch focus to other social units, such as CBOs, with explicitly gendered activities. Redefining the unit of analysis from the household to a social actor like a women's CBO can forefront the agency possible in transforming or even disrupting cultural symbols and identities, as well as the potential power of this activity in livelihood struggles.

The examination of women's CBOs in Calakmul and their activities can assist us in understanding livelihoods as gendered. Thinking about transformative struggles to reshape identities, lives, and relationships requires thinking about how identity is produced (Sundberg 2004), performed (Butler 1990), and strategically deployed (Rocheleau and Radel 1999). Individuals and groups reshape, negotiate, and represent their identities as parts of livelihood strategies. Socio-environmental identities have been prominent in these efforts, due to the centrality of environmental resources (or natural capital) to many people's livelihoods, particularly in the rural Global South. In turn, the role of gendered ideology in livelihood production highlights the potential limitations of utilizing a capital assets framework alone for understanding gendered livelihoods. The reshaping of gendered socio-environmental identities can form a key component to individuals' livelihood strategies. Thus livelihoods include struggles to transform or disrupt ideologies, including gender ideologies. And in this manner, gender becomes central to livelihood struggles.

Geographers, and political ecologists more specifically, need to better understand the links between socio-environmental identities on the one hand, and resource access and livelihood struggles on the other. These links are more complicated than either natural convergences between conservation and (in this case) women's gender interests or simple strategic identity deployments for materialist goals (Brosius 1999; Rocheleau and Radel 1999). As such, the case study presented here constitutes important additional empirical work on these linkages, as well as on the role of conservation in changing gender relations. The case also further refines an aspect of the FPE framework and contributes to our overall understanding of gendered humanenvironment relations, their linked material and ideological outcomes, and the nature of rural women's agency within such relations.

\section{Acknowledgements}

This article grew out my doctoral dissertation, fieldwork for which was supported by a Fulbright-Hays Doctoral Dissertation Research Fellowship and a National Science Foundation Doctoral Dissertation 
Improvement Grant. I also received an AAUW Short-Term Research Publication Grant in support of this article. I owe additional thanks to three anonymous reviewers for their helpful insights and suggestions on the earlier article draft.

\section{Notes}

1. I use the notion of gender ideology to refer to structures of power operating through systems of signification, by which attitudes regarding appropriate roles, rights, and responsibilities of women versus men are communicated and enforced. More simply put, I use gender ideology to refer to an idealized vision of gender relations and norms (Silvey 2000), which is always and necessarily associated with relations of power.

2. I employ the concept of identity to refer to the dual construction of the individual both in terms of the individual's sense of self and in terms of the labeling of the individual by others or by society. Identities should be thought of as shifting, contingent, and relational (Harding 1998; Haraway 1991), and are both constructed and performed through ordinary, daily practices (Butler 1990; McDowell 1995).

3. I have changed the names of the ejidos to protect the anonymity of the residents.

4. Some villages in the region can be characterized as primarily indigenous (e.g. Chol Maya) or as mixed, but the majority of villages are best characterized as non-indigenous, or mestizo (a term referring to the mixed descendants of Hispanic colonizers and native populations, and inferring a status of participation in the dominant national Mexican ethnic identity).

5. I have chosen not to include results from one CBO in the interests of article length and based on a judgment that including this group would add little to my arguments here.

6. I also interviewed numerous CBO members as a part of the 100 -household interviews described above.

7. I gained experience with PRA techniques through a previous vocation as a community development worker in Colombia.

8. I present the results of two of these activities here. In a third activity, which I do not present here, I asked the women to draw a picture of their CBO land, including crops cultivated and other land uses. I asked them to do this twice - first for the plot of land as it currently was and second for how they would like the plot to look five years from now. For CBOs that collectively cultivated their land, the women drew these two pictures together as a group. For CBOs that had sub-divided their land into small individual plots, the women drew their pictures independently.

9. My son did accompany me to each community on various occasions. As a result, most of the women had previously met my son.

10. The dichotomization of productive and reproductive labor is analytically problematic (Sachs 1996), but I use the distinction here in line with its construction within the dominant gender ideology in order to emphasize the role of the drawings in transgressing that ideology or not.

11. A roto-tiller is also known as a rotary cultivator.

12. Ejidatarios are formal member of the ejido, with associated rights (including land rights), and are primarily men.

13. The ejidal assembly is the local governing body for the ejido and is made up of all ejidatarios.

14. Procampo was a federal program to pay farmers for the cultivation of certain crops, as part of an effort to ease the pain of neoliberal adjustments required under the North American Free Trade Act implemented in 1994.

15 . Participation was also subject to negotiations among women. For many women, participation in the CBO required another woman (often a daughter, mother, or mother-in-law) to substitute her labor for the labor of the CBO member (allowing the member to attend meetings and work the CBO land). 
16. I employ a quantitative approach to examine outcomes of land access and control in two previously published articles (Radel 2005, 2012).

\section{Notes on contributor}

Claudia Radel is Assistant Professor of Human Geography in the College of Natural Resources at Utah State University, where her research explores changing natural resource-based livelihood strategies for individuals, households, and communities in the rural global south. She is interested particularly in how gender ideologies and practices intersect with these strategies. Her research also examines the gendered dimensions of natural resource access, control, and decision-making. She has a $\mathrm{PhD}$ in Geography from Clark University and a MPA in International Development from Princeton University.

\section{References}

Arizpe, L. and C. Botey. 1987. Mexican agricultural development policy and its impact on rural women. In Rural women and state policy: Feminist perspectives on Latin American agricultural development, eds. C.D. Deere and M. León, 67-83. Boulder: Westview Press.

Basset, T. 2002. Women's cotton and the spaces of gender politics in northern Cote d'Ivoire. Gender, Place and Culture 9, no. 4: 351-70.

Brosius, J. P. 1999. Analyses and interventions: Anthropological engagements with environmentalism. Current Anthropology 40, no. 3: 277-310.

Butler, J. 1990. Gender trouble: Feminism and the subversion of identity. New York: Routledge.

Carney, J. 1993. Converting the wetlands, engendering the environment: The intersection of gender with agrarian change in the Gambia. Economic Geography. 69, no. 4: 329-48.

Chambers, R. 1994a. Participatory rural appraisal (PRA): Analysis of experience. World Development 22, no. 9: 1253-68.

Chambers, R. 1994b. The origins and practice of participatory rural appraisal. World Development 22, no. 7: 953-69.

Chambers, R. and G.R. Conway, 1991. Sustainable rural livelihoods: Practical concepts for the 21st century. IDS Discussion Paper 296.

De Janvry, A. and E. Sadoulet. 2001. Income strategies among rural households in Mexico: The role of off-farm activities. World Development 29, no. 3: 467-80.

Deere, C.D. and M. León. 2003. The gender asset gap: Land in Latin America. World Development 31, no. 6: 925-47.

Fleming, R. 2009. Creative economic development, sustainability, and exclusion in rural areas. Geographical Review 99, no. 1: 61-80. 
Flora, C.B. 2001. Access and control of resources: Lessons from the SANREM CRSP. Agriculture and Human Values 18: 41-8.

Freire, P. 1986. Pedagogy of the oppressed. New York: Continuum.

Godquin, M. and A.R. Quisumbing. 2008. Separate but equal? The gendered nature of social capital in rural Philippine communities. Journal of International Development 20: 13-33.

Gravel, N. 2007. Mexican smallholder adrift: The urgent need for a new social contract in rural Mexico. Journal of Latin American Geography 6, no. 2: 77-98.

Gururani, S. 2002. Forests of pleasure and pain: Gendered practices of labor and livelihood in the forests of the Kumaon Himalayas. Gender, Place and Culture 9, no. 3: 229-43.

Haenn, N. 1999. The power of environmental knowledge: Ethnoecology and environmental conflicts in Mexican conservation. Human Ecology 27, no. 3: 477-91.

Haenn, N. 2005. Fields of power, forests of discontent: Culture, conservation, and the state in Mexico. Tucson: University of Arizona Press.

Haraway, D. 1991. Simians, cyborgs, and woman: The reinvention of nature. New York: Routledge.

Harding, S. 1998. Is science multi-cultural? Postcolonialisms, feminisms, and epistemologies. Bloomington: Indiana University Press.

Jackson, C. 1998. Gender, irrigation, and environment: Arguing for agency. Agriculture and Human Values 15, 313-24.

Jackson, C. and M. Chattopadhyay. 2000. Identities and livelihoods: Gender, ethnicity and nature in a South Bihar village. In Agrarian environments: Resources, representation, and rules in India, eds. A. Agrawal and K. Sivaramakrishnan, 147-69. Durham, NC: Duke University Press.

Klepeis, P. and R. Roy Chowdhury. 2004. Institutions, organizations, and policy affecting land change: Complexity within and beyond the ejido. In Integrated land-change science and tropical deforestation in the southern Yucatán: Final frontiers, eds. B.L. Turner, II, J. Geoghegan, and D. Foster, 145-69. Oxford: Oxford University Press.

Oberhauser, A.M., J.L. Mandel, and H.M. Hapke. 2004. Gendered livelihoods in diverse global contexts: An introduction. Gender, Place and Culture 11, no. 2: 205-8.

Leach, M. 2007. Earth mother myths and other ecofeminist fables: How a strategic notion rose and fell. Development and Change 38, no. 1: 67-85.

Liepins, R. 2000. Making men: The construction and representation of agriculture-based masculinities in Australia and New Zealand. Rural Sociology 65, no. 4: 605-20. 
McDowell, L. 1995. Body work: Heterosexual gender performances in city workplaces. In Mapping desire, eds. D. Bell and G. Valentine, 75-95. New York: Routledge.

Mollet, S. 2006. Race and natural resource conflicts in Honduras: The Miskito and Garifuna struggle for Lasa Pulan. Latin American Research Review 41, no. 1: 76-101.

Molyneux, M. 2002. Gender and the silences of social capital: Lessons from Latin America. Development and Change 33, no. 2: 167-88.

Murphy, J. 1998. Ways of working in the forest: Mediating sustainable development in Calakmul. Paper presented at the Annual Meeting of the American Anthropological Association, in Philadelphia, PA.

Nightingale, A. 2006. The nature of gender: Work, gender, and environment. Environment and Planning D: Society and Space 24: 165-85.

Perreault, T. 2001. Developing identities: Indigenous mobilization, rural livelihoods, and resource access in Ecuadorian Amazonia. Ecumene 8, no. 4: 381-413.

Pulido, L. 1996. Environmentalism and economic justice: Two Chicano struggles in the Southwest. Tucson: University of Arizona Press.

Radel, C. 2005. Women's community-based organizations, conservation projects, and effective land control in southern Mexico. Journal of Latin American Geography 4, no. 2: 9-36.

Radel, C. 2011. Becoming farmers: Opening spaces for women’s resource control in Calakmul, Mexico. Latin American Research Review 46, no. 2: 29-54.

Radel, C. 2012. Outcomes of conservation alliances with women's community-based organizations in southern Mexico. Society \& Natural Resources 25(1): 52-70.

Radel, C. and B. Schmook. 2008. Male transnational migration and its linkages to land use change in a southern Campeche ejido. Journal of Latin American Geography 7, no. 2: 59-84.

Rakodi, C. 1999. A capital assets framework for analyzing household livelihood strategies: Implications for policy. Development Policy Review 17: 315-42.

Razavi, S, ed. 2003. Agrarian change, gender and land rights. Special issue, Journal of Agrarian Change 3, nos. 1-2.

Rocheleau, D. and D. Edmunds. 1997. Women, men and trees: Gender, power and property in forest and agrarian landscapes. World Development 25, no. 8: 1351-71.

Rocheleau, D. and C. Radel. 1999. Comment on: Anthropological engagements with environmentalism, by J. P. Brosius. Current Anthropology 40, no. 3: 296-7. 
Rocheleau, D., L. Ross, J. Morrobel, L. Malaret, R. Hernandez, and T. Kominiak. 2001. Complex communities and emerging ecologies in the regional agroforest of Zambrana-Chacuey, Dominican Republic. Ecumene 8, no. 4: 465-92.

Rocheleau, D., B. Thomas-Slayter, and E. Wangari. 1996. Gender and environment: A feminist political ecology perspective. In Feminist political ecology: Global issues and local experiences, ed. D. Rocheleau, B. Thomas-Slayter, and E. Wangari, 3-23. New York: Routledge.

Sachs, C. 1983. The invisible farmers: Women in agricultural production. Totowa, NJ: Rowman \& Littlefield.

Sachs, C. 1996. Gendered fields: Rural women, agriculture, and environment. Boulder: Westview Press.

Sandilands, C. 2005. Where the mountain men meet the lesbian rangers: Gender, nation, and nature in the Rocky Mountain National Parks. In This elusive land: Women and the Canadian environment, eds. M. Hessing, R. Raglon, and C. Sandilands, 142-62. Vancouver: UBC Press.

Schmook, B. and C. Vance. 2009. Agricultural policy, market barriers, and deforestation: The case of Mexico’s southern Yucatán. World Development 37, no. 5: 1015-25.

Schroeder, R. 1999. Shady practices: Agroforestry and gender politics in the Gambia. Berkeley: University of California Press.

Silvey, R. 2000. Stigmatized spaces: Gender and mobility under crisis in South Sulawesi, Indonesia. Gender, Place and Culture 7, no. 2: 143-61.

Silvey, R. and R. Elmhirst. 2003. Engendering social capital: Women workers and rural-urban networks in Indonesia's crisis. World Development 31, no. 5: 865-79.

Sundberg, J. 2004. Identities in the making: Conservation, gender and race in the Maya Biosphere Reserve, Guatemala. Gender, Place and Culture 11, no. 1: 43-66.

Trauger, A. 2004. 'Because they can do the work': Women farmers and sustainable agriculture in Pennsylvania, USA. Gender, Place and Culture 11, no. 2: 289-307.

Winters, P. and B. Davis. 2009. Designing a programme to support smallholder agriculture in Mexico: Lessons from PROCAMPO and Oportunidades. Development Policy Review 27, no. 5: 617-42.

Zapata, E. 1996. Modernization, adjustment, and peasant production: A gender analysis. Latin American Perspectives 23, no. 1: 118-30. 